\title{
Stem Cells in Periodontal Regeneration
}

\author{
Shalini $\mathrm{H}^{1}$, Dr. Sankari ${ }^{2}$ \\ (Department of Periodontia, SaveethaDental College, India) \\ (Department of Periodontia, Saveetha Dental College, India)
}

\begin{abstract}
Periodontitis is an inflammatory disease which results in clinical loss of supporting periodontal tissues including the periodontal ligament, cementum and alveolar bone. For decades, periodontologists have sought various surgical and non-surgical procedures to repair the damage. But, the ultimate aim of regeneration has not been achieved. This review is about the application of stem cells in periodontal regeneration. The triad inclusive of cells, signalling molecules and scaffold plays a significant role in achieving regeneration.
\end{abstract}

Keywords: Periodontal ligamentstem cells, regeneration, scaffold, signalling molecules, tissueengineering,

\section{Introduction}

Periodontitis is a disease of the periodontium characterized by irreversible loss of connective tissue attachment and supporting alveolar bone $\mathrm{e}^{[1]}$. It is a highly prevalent chronic inflammatory disease ${ }^{[2]}$. Various surgical and nonsurgical treatment procedures were followed since 1950s which had resulted in arresting the progression of periodontitis and had helped in tissue healing. But the ultimate goal of regeneration of lost periodontal structures remains questionable.

Periodontal regeneration aims at complete restoration of the lost tissues to their original architecture and function by recapitulating the crucial wound healing events associated with their development ${ }^{[2]}$. This entails the reformation of all the components of the periodontium, gingival connective tissue, periodontal ligament, cementum, and alveolar bone. This had led to the introduction of stem cells in periodontal regeneration.

1993, Langer and Colleagues ${ }^{[3]}$ proposed tissue engineering as a possible technique for regenerating lost tissue and restoration of various human tissues and organs in starting to become a reality.

\section{History of stem cells:}

\section{Stem Cells}

Stem cell refers to a clonogenic, undifferentiated cell that is capable of self-renewal and multi-lineage differentiation ${ }^{[4]}$. They form the origin of life. They are unique and form the basis of development, growth and survival of a living organism. Stem cells are the foundation cells of every organ and tissue in the body including the periodontium ${ }^{[5,6]}$.

The term stem cell appeared first in the literature during $19^{\text {th }}$ century ${ }^{[7]}$. Birth of stem cell research took place way back in 1953 when Leroy Stevens identified teratoma like cells in testicles of inbred mice. The concept that stem cells may reside in the periodontal tissues was first proposed approximately 20 years ago by Melcher, who queried whether the three cell population of the periodontium (cementoblasts, osteoblasts, and periodontal ligament fibroblasts) were derived from a single population of ancestral cells or stem cells ${ }^{[8]}$. The most compelling evidence that these cells are present within the periodontal tissues has been provided by the studies of Mc Culloch et al (1987) who identified small population of progenitor cells adjacent to blood vessels within the periodontal ligament ${ }^{[9]}$.

\subsection{Embryonic stem cells}

\section{Stem cells-types ${ }^{[10-12]}$ :}

\subsection{Foetal stem cells}

1.3. Adult stem cells- Haematopoietic stem cells

Non haematopoietic stem cells (bone

Marrow stromal stem cells or

Mesenchymal stem cells)

\subsection{Humanderived mesenchymal stem cells (dental origin)}

- dental pulp derived stem cells

- stem cells from exfoliated human deciduous teeth

- Adult periodontal ligament stem cells 
- Root apical papilla stem cells

- dental follicle stem cells

- Mesenchymal stem cells from gingiva

\subsection{Human derived mesenchymal stem cells (non-dental origin)}

- Bone marrow derived mesenchymal stem cells

- Adipose derived stem cells

\section{Terminologies ${ }^{[13]}$ :}

3.1 Progenitor cell:It is an undifferentiated precursor cell with the capacity to undergo differentiation into specialised cell types; unlike putative stem cells they do not retain the capacity for self-renewal.

3.2 Totipotent stem cell:they are cells derived from the first few divisions of the fertilised egg which have the potential to give rise to all the differentiated cells of the fully developed organism.

3.3 Pluripotent stem cell:they are cells capable of self-renewing and differentiating into any of the germ layers(ectoderm, endoderm, mesoderm)

3.4Multipotent stem cell: cells that self-renew and differentiate into several different specialised cell types, often within a tissue (e.g. haematopoietic stem cells)

\section{Differences between :}

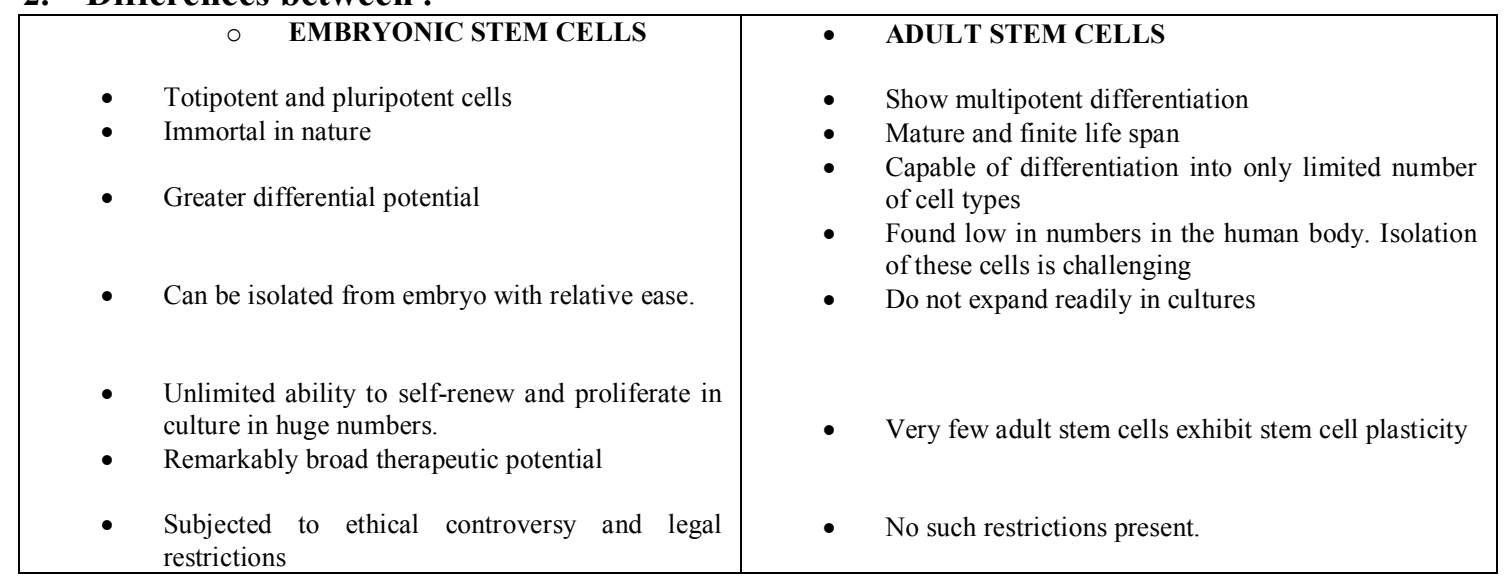

\section{Ethical concerns:}

Although stem cell population are present in foetus during gestation, their roles in normal development have been widely studied, their possible clinical usefulness has barely been explored, owing to the ethical issues of using cells from the foetus in treating disease and risks to pregnancy associated with intrauterine procedures $^{[14]}$

\section{Stem cell banking:}

In 2005 , the National academics ${ }^{[15]}$ issued a report, cord blood establishing a National haematopoietic stem cell bank program, which recommended that a national cord blood bank be established to harness the medical potential of these sources of stem cells. Research in recent times indicates that umbilical cord blood is rich in "stem cells" ${ }^{[16]}$. Those cells have important advantages compared to the bone marrow stem cells. The major advantage that umbilical cord blood stem cells are easier to gather that stem cells from the bone marrow. They have a unique ability to regenerate, reproduce into over 200 types of tissues. Above all, such stem cells can be collected from the umbilical cord of child can be frozen and kept in a tank; which can be used later ${ }^{[17]}$.

The first ever cord blood bank in the world was started in New York's Milstein National cord blood Centre. Today, there are over 40 cord blood banks worldwide, both public and private ${ }^{[16]}$

\section{Tissue Engineering}

It is a specialised field of science based on principles of cell biology, developmental biology and biomaterials science to fabricate new tissues to replace lost or damaged tissues ${ }^{[18-20]}$. 


\section{Triad of tissue engineering:}

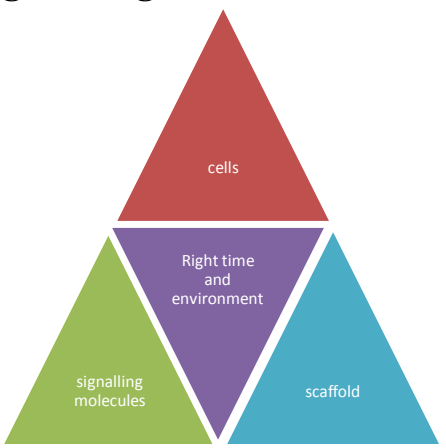

The tissue engineering approach to bone and periodontal regeneration combines 3 key elements to enhance regeneration ${ }^{21]}$

1.1 Cells

1.2. Conductive scaffold

1.3. Signalling molecules

1.1. Cells:stem cells are considered as a major component of tissue engineering process. Stem/progenitor cells contribute to regeneration process. Different types of stem cells used in this process includes

\subsubsection{Periodontal ligament derived mesenchymal stem cells:}

They are first isolated from the periodontal ligament tissues of extracted human third molar teeth, followed by the periodontal ligament from the root surface following extraction, periodontal ligament remaining in the alveolar bone surfaces of the extraction sockets. These cells are multipotent and can differentiate into osteoblasts, fibroblasts and periodontal ligament like tissues.

\subsubsection{Root apical papilla stem cells:}

They are obtained from the tips of growing tooth roots which represent a unique population of dental stem cells (SCAP). They have the capacity to differentiate into adipocytes, odontoblasts and osteoblasts in vitro.

\subsubsection{Dental follicle cells:}

They are multipotent and contain progenitors for cementoblasts, periodontal ligament and osteoblasts.

\subsubsection{Dental pulp stem cells:}

They have the ability to terminally differentiate into odontoblasts like cells to form

Bone, representing a potential stem cell sources for stem cell therapy.

\subsubsection{Human gingiva}

Tomas I. Mitrano et al in 2010 studied if gingival connective tissue could be a reservoir of MSCs that could be used in regenerative procedures based on tissue engineering ${ }^{[22]}$. The results clearly demonstrated that it is possible to isolate MSCs from the gingival connective tissue and obtain their differentiation into osteoblasts, cartilage and adipose cells in the same way that has been described regarding samples obtained from the bone marrow $^{[22]}$.

1.1.6 Stem cells of non- dental origininclusive of bone marrow derived mesenchymal stem cells and adipose derived stem cells.

\subsection{Conductive Scaffold:}

The role of scaffold is to provide support for delivering cells and growth factors to the proposed site of tissue regeneration. Regeneration of any tissue requires a physical support to the cells. They should

- Be biodegradable. The rate of degradation should coincide with rate of tissue formation ${ }^{[23]}$.

- Should be porous for the diffusion of cells and nutrients ${ }^{[24]}$. Allow appropriate differentiation of cells without affecting their progeny.

- They should ideally mimic the natural environment of tissues.

- They should be biocompatible and non -immunogenic ${ }^{[25]}$.

They are available in both natural and synthetic forms. Natural biomaterials used as scaffold includes collagen, chitosan, alginate and fibrin, agarose, gelatin, hyaluronic acid and pectin. 
Synthetic biomaterials includes polygycolicacid, poly lactic acid, and their copolymers

\subsection{Signalling molecules:}

The availability of cells and substrate alone do not serve the purpose of tissue engineering. Here comes the

Role of instructive messages in a prefabricated 3-dimensional construct (signalling molecule).

Growth factors and enamel matrix proteins have a proven role in controlling the behaviour of cells within the periodontal tissues. The most studied growth factors in periodontal regeneration include platelet derived growth factor (PDGF), epidermal growth factor (EGF), FGF, IGF and different BMPs.

PGDF seems to have a positive effect in periodontal healing and regeneration ${ }^{[26-29]}$. A wide range of evidence from periodontal regeneration studies indicate that BMPs are capable of inducing formation of new alveolar bone and cementum ${ }^{[30-32]}$. The rationale for the potential use of enamel matrix proteins in periodontal tissue regeneration therapies is justified by the initial cementum formation during the normal development of tooth attachment apparatus ${ }^{[33,34]}$. Commercially available emdogain have been suggested to stimulate the formation of root cementum ${ }^{[35]}$. It also acts a signalling molecule which can regulate the activity of follicle cells, periodontal ligament cells, odontoblasts, gingival fibroblasts and cementoblasts ${ }^{[36-41]}$.

\section{Bio patch:}

\section{Current Advances:}

They are Nano-sized plasmids carrying the genetic instructions (DNA) for making bone.It is a nonviral gene delivery system for bone regeneration wherein collagen scaffold is utilised to deliver polyethylenimine (PEI) - plasmid DNA (pDNA) encoding platelet derived growth factor-B(PDGF-B) complexes ${ }^{[42]}$.

2. PRF membrane: The second generation platelet rich fibrin has many uses in periodontal therapy as a graft,in management of intrabony defects, recession coverage, and in ridge augmentation. But recently, it could also be used as scaffold for stem cell therapy. For the first time, platelet rich fibrin membrane was used as a scaffold for periosteal tissue regeneration (invitro) ${ }^{[43]}$. PRF preparations are known to contain platelets, growth factors such as PDGF, TGF- $\beta$, IGF-I which promotes cell proliferation ${ }^{[4]}$. It is a biocompatible natural scaffold with signalling molecule at a lower cost.

\section{Hertwig's epithelial root sheath / Epithelial cell rests of malassez in periodontal regeneration}

Epithelial cell rests of malassez are the only odontogenic epithelial population in the periodontal ligament. Studies had proved that the combination of Hertwig's epithelial root sheath/epithelial cell rests of malassez and dental mesenchymal stromal/stem cell populations give rise to better outcomes in periodontal regeneration ${ }^{[45-47]}$. Dental pulp cells in combination with porcine epithelial cell rests of malassez can differentiate into ameloblast like cells and generate enamel like tissues, invivo, as shown by positive amelogenin staining ${ }^{[47]}$.

Co-culture of dental follicle cells and Hertwig's epithelial root sheath cells significantly increase bone/cementum related gene expression ${ }^{[45]}$.

\section{Conclusion:}

Tremendous research in stem cell therapy is in the path of making it a realistic alternative in periodontal regeneration. The availability of stem cells, scaffold and signalling molecules will give rise to a predictable outcome in the near future. Further research is still needed regarding appropriate signalling molecules coding for individual tissues in periodontal attachment apparatus. The delivery of right signals at the right time mimicking normal embryological development can only pave the way for a successful regeneration.

\section{References:}

[1] Pihlstrom BL, Michalowicz BS, Johnson NW, Periodontal diseases, Lancet 366, 2005, 1809-1820.

[2] Polimeni G, Xiropaidis AV, Wikesjo UM. Biology and principles of periodontal wound healing /regeneration. Periodontol, 41, 2000 2006, 30-47.

[3] Langer R, Vacanti JP. Tissue engineering. Science 260(5110),1993, 920-6.

[4] Smith A, A glossary for stem cell biology. Nature 441,2006,1060.

[5] Ten cate AR, The development of the periodontium-a largely ectomesenchymally derived unit,Periodontol 2000 13,1997,9-19.

[6] Thesleff I, Tummers M. Stem cells and tissue engineering: prospects for regenerating tissues in dental practice. Med Princpract,12(suppl.1),2003,43-50.

[7] Lin NH, Gronthos S, Bartold PM. Stem cells and periodontal regeneration. Australian Dental journal,53, 2008,108-21.

[8] Melcher, AH. Annals of the royal college of surgeons of England67,1985,130-131.

[9] Mcculloch,CA, Nemeth E, Lowenberg. B,Melcher, AH, The anatomicalrecord,219,1987,233-242.

[10] PeraMF;CooperS.MillsJ.ParringtonJM.Isolation and characterisation of a multipotent clone of human embryonal carcinoma cells. Differentiation,42,1989,10-23.

[11] Thompson JA, Itskovitz-EldorJ.Shapiro SS, Waknitz MA, Swiergiel JJ. Marshall VS, etal.Embryonic stem cell lines derived from human blastocysts. Science ,282,1998,1145-7. 
[12] ShamblottMJ.Axelman J. Wang S, Bugg EM, Littlefield JW, Donovan PJ et al. Derivation of pluripotent stem cell lines from cultured human primordial germ cells. ProcNatlAcadSciUSA ,95,1998,13726-31.

[13] Stem cells: a new paradigm in periodontal regeneration,International journal ofmedical research and health sciences,(2),254-255.

[14] Campagnoli C. Roberts IA, Kumar S, Bennett PR, BellantuonoI,Fisk NM. Identification of mesenchymal stem/ progenitor cells in human first trimester fetal blood, liver, and bone marrow, blood,98,2001,2396-402.

[15] Understanding stem cells: An overview of the science and issues from National Academics[internet]. Available from: http://www.national- academics.org. [last accessed on $2009 \mathrm{dec} 01$ ].

[16] Umbilical cord blood banking [internet]. Available from :http://www.chillibreeze.com [last accessed on 2009 dec 01$]$.

[17] India's first public stem cell bank[internet]. Available from:http://www.rediff_com news. [last accessed on 2009 dec 01$].$

[18] Langer R, Tirrell DA. Designing materials for biology and medicine. Nature, $\overline{4} 28,2004,487-492$.

[19] Narem R, Sambanis A, Tissue engineering: from biology to biological structures. Tissue eng, 1,1995,3-13.

[20] Slavkin HC, Bartold PM, Challenges and potential in tissue engineering. Periodontal,41,2000 2006,9-15.

[21] Tissue engineering: Applications in maxillofacial surgery and periodondics. Chicago Quintessence, Lynch SE (2008).

[22] Tomas IM, Melisa SG, Flavio C, Estefania NL, Patricia AL, Francisca SF, Antonio Q, Alejandra C, and Antonio S. Culture and Characterization of Mesenchymal Stem Cells From Human Gingival Tissue. J Periodontol,81, 2010,917-25.

[23] Freed LE, Vunjak-Novakovic G, Biron RJ, et al. Biodegradable polymer scaffolds for tissue engineering. Biotechnology (N Y), 12, 1994, 689-93.

[24] Sachlos E, Czernuszka JT. Making tissue engineering scaffolds work. Review: the application of solid freeform fabrication technology to the production of tissue engineering scaffolds, Eur Cell Mater,30, 2003,29-39.

[25] Almeida HA, BartoloPJ . Structural and vascular analysis of tissue engineering scaffolds, part 2: topology optimisation. Methods MolBiol,868, 2012, 209

[26] Glannobile WV, Hernandez RA,Finkelman RD, et al. Comparative effects of platelet-derived growth factor-BB and insulin-like growth factor-I, individually andin combination, on periodontal regeneration in Macacafascicularis. J PeriodontalRes, 31,1996, 301-12.

[27] Lynch SE, Williams RC, Polson AM, et al. A combination of platelet-derivedandinsulin-like growth factors enhances periodontalregeneration. J Clinperiodontal, 16, 1989, 545-8.

[28] Howell TH, Fiorellini JP, Paquette DW,et al. A phase I/II clinical trial to evaluate a combination of recombinant human plateletderived growth factor-BB and recombinant human insulin-like growth factor-I in patients with periodontal disease. $J$ Periodontol,68, 1997, 1186-93.

[29] NevinsM,Giannobile WV, McGuire MK, et al. Platelet-derived growth factorstimulates bone fill and rate of Attachment level gain: results of a large multicenterrandomized controlled trial. J Periodontol,76,2005, 2205-15.

[30] Wikesjo UM, Qahash M, Thomson RC,et al. rhBMP-2 significantly enhancesguided bone regeneration. Clin Oral Implants Res, 15, 2004, 194-204.

[31] Kemoun P, Laurencin-Dalicieux S, Rue J,et al. Human dental follicle cells acquirecementoblast features under stimulation by BMP2/-7 and enamel matrix derivatives (EMD) in vitro. Cell Tissue Res,329, 2007, 283-94.

[32] Zhao M, Xiao G, Berry JE, et al. Bone morphogenetic protein 2 induces dental follicle cells to differentiate toward a cementoblast/osteoblast phenotype. J Bone Miner Res, 17, 2002, 1441-51.

[33] Hammarstrom L. Enamel matrix, cementum development and regeneration. J ClinPeriodontol,24, 1997, 658-68.

[34] Gestrelius S, Lyngstadaas SP, Hammarstrom L. Emdogain-periodontal regeneration based on biomimicry. Clin Oral Investig,4, 2000, 120-5.

[35] Kemoun P, Laurencin-Dalicieux S, Rue J, et al. Human dental follicle cells acquirecementoblast features under stimulation by BMP-2/-7 and enamel matrix derivatives (EMD) in vitro.Cell Tissue Res,329, 2007, $283-94$.

[36] Nagano T, Iwata T, Ogata Y, et al. Effect of heat treatment on bioactivities of enamel matrix derivatives in human periodontal ligament (HPDL) cells. J Periodontal Res,39, 2004, 249-56.

[37] Lyngstadaas SP, Lundberg E,Ekdahl H, et al. Autocrine growth factors in humanperiodontal ligament cells cultured on enamel matrix derivative. J ClinPeriodontol,28, 2001, 181-8.

[38] Carinci F, Piattelli A, Guida L, et al.Effects of Emdogain on osteoblast geneexpression. Oral Dis, 12, 2006, 329-42.

[39] ZeldichE,Koren R, Dard M, et al. Enamel matrix derivative protects humangingival fibroblasts from TNF-induced apoptosis by inhibiting caspase activation. $J$ cell Physiol,213, 2007, 750-8.

[40] Veis A, Tompkins K, Alvares K, et al. Specific amelogenin gene splice products have signaling effects on cells in culture and In implants in vivo. $J$ Biol Chem,275, 2000; 41263-72.

[41]. Messenger MP, Raif el M, Seedhom BB, et al. The potential use of enamel matrix derivative for in situ anterior cruciate ligament tissue engineering: a translational in vitro investigation. Tissue Eng, 13, 2007, 2041-51.

[42] SatheeshElangovan, Sheetal R. D'Mello, Liu Hong, Ryan D. Ross, Chantal Allamargot, Deborah V.Dawson, ClarkM.Stanford, Georgia K. Johnson, D. Rick Sumner, Aliasger K. Salem, The enhancement of bone regeneration by gene activated matrix encoding for platelet derived growth factor, Journal of biomaterials,35(2), Jan 2014, 737-747.

[43] Gassling V, Douglas T,Warnke, PH, Acil Y, Wiltfang J, .Becker ST, Platelet rich fibrin membrane as scaffolds for periosteal tissue engineering. Clin.Oral Impl. Res. 21, 2010,543-549.

[44] Lundquist, R., Dziegiel, M.H. \&Agren,M.S. (2008) Bioactivity and stability of endogenous fibrogenic factors in platelet-rich fibrin. Wound Repair and Regeneration 16: 356-363

[45] Bai Y, Matsuzaka K, Hashimoto S, Fukuyama T, Wu L, Miwa T, Liu X, Wang X, Inoue T. Cementum and periodontal ligament like tissue formation by dental follicle Cell sheets co-cultured with the Hertwig's epithelial root sheath. Bone 48, 2011,1417-1426.

[46] Jung HS, Lee DS, Lee JH, Park SJ, Lee G, Seo BM, Ko JS, Park JC. Directing the differentiation of human dental follicle cells into cementoblasts and /or osteoblasts by a combination of HERS and pulp cells. J Mol Histol,42,227-235.

[47]. Shinmura Y, Tsuchiya S, Hata K, Honda MJ. Quiescent the epithelial cell rests of Malassez can differentiate into ameloblast- like cells. J Cell Physiol,217,2008,728-738. 